\title{
Study on the Gel Cleaning System for Removal of Poly (vinyl acetate) Fixative of the Mural Paintings of the Payathonzu Temple in Bagan, Myanmar (I) - Focusing on Properties and Removability of Gel Cleaners -
}

\author{
Yeong Gyeong $\mathrm{Yu}^{1}$, Gyu-Seong $\mathrm{Han}^{2}$, Hwa Soo Lee ${ }^{3,}{ }^{,}$, Kyeong Soon $\mathrm{Han}^{3}$ \\ ${ }^{l}$ Institute of Conservation of Paintings, Konkuk University, Chungju 27278, Korea \\ ${ }^{2}$ Department of Wood and Paper Science, Chungbuk National University, Cheongju 28644, Korea \\ ${ }^{3}$ Department of Fine Arts, Konkuk University, Chungju 27278, Korea
}

\author{
Received August 1, 2021 \\ Revised August 10, 2021 \\ Accepted August 12, 2021 \\ *Corresponding author \\ E-mail: comp@kku.ac.kr \\ Phone: +82-43-840-3672 \\ Journal of Conservation Science \\ 2021;37(4):370-379 \\ https://doi.org/10.12654/JCS.2021. \\ 37.4 .06 \\ pISSN: 1225-5459, eISSN: 2287-9781 \\ (C) The Korean Society of \\ Conservation Science for Cultural \\ Heritage \\ This is an Open-Access article distributed \\ under the terms of the Creative \\ Commons Attribution Non-Commercial \\ License (http://creativecommons.org/ \\ licenses/by-nc/3.0) which permits \\ unrestricted non-commercial use, \\ distribution, and reproduction in any \\ medium, provided the original work is \\ properly cited.
}

\begin{abstract}
In the past, PVAc [poly(vinyl acetate)] was used as a fixative for the conservation of the murals in the murals of the Payathonzu temple located in Bagan, Myanmar. In this study, attention was paid to gel cleaning as a method for stably removing such PVAc fixatives. Based on the recent research trend related to the cleaning of murals in Bagan ruins, 3 types of gelling agents (Nevek ${ }^{\circledR}$, Laponite ${ }^{\circledR} \mathrm{RD}$, Carbopol ${ }^{\circledR} 980$ ) and 2 types of organic solvents (Acetone, Dimethyl carbonate) were selected. Six types of gel cleaners were prepared by mixing gelling agents and organic solvents, and the properties and fixative removability of these cleaners were compared. As a result of confirming the properties of the prepared gel cleaners, the $\mathrm{pH}$ of the cleaners was all in the weak acidic to weakly alkaline range, which was a stable condition for mural application. Also, there was no difference in the viscosity of the cleaners depending on the type of solvent, but there was a difference depending on the type of gelling agent used. Regarding the weight loss ratio of PVAc, which is an indicator of removability, the exposure conditions of the gel cleaners, the boiling point of the solvent used, and the viscosity of the gelling agent acted as factors affecting. As a result of comparing the removability of gel cleaners, it was confirmed that the solvent's fixative solubility, the volatility of the solvent itself, and the solvent release control properties of the gelling agent had a great effect on the removability of the gel cleaners. In Part 2, the stability and the running applicability of the gel cleaners will be investigated by making mockup samples reflecting the properties of the materials and techniques used to produce the mural paintings in the Payathonzu Temple.
\end{abstract}

Key Words Payathonzu temple, Mural paintings, Gel cleaning system, PVAc, Conservation

\section{INTRODUCTION}

The Bagan ruins are the largest concentration of Buddhist heritage in Myanmar, in which the remains of 2,834 buildings between the $10^{\text {th }}$ and $13^{\text {th }}$ centuries survive. Among them, 447 temples are decorated with colorful mural paintings (Lunsford, 2017). However, major earthquakes in 1975 and 2016 caused a damage in Bagan, and the Myanmar government and international organizations have been working to restore the temples and conserve the murals. After the earthquake in 2016, surveys and research were also conducted in Korea for the conservation treatment of the murals of the Payathonzu Temple. As a result of reviewing the conditions of the murals, it was concluded that the murals needed conservation treatment due to material degradation over a long period of time and damage caused by repair materials used in the past (Korea Culture Heritage Foundation et al., 2018; 2019). In particular, the areas where the painting layers received thick fixative treatment in the past were highly polished, stained, and discolored. Excessive fixative treatment forms a film on the surface of the painting layer, and the layer of fixatives can accelerate deformation and deterioration of the painting layer according to temperature and humidity changes (Lee et al., 2015). Therefore, research 
on stabilizing the painting layer is required to prevent damage to the painting layer of murals that received excessive fixing treatment. Recently, studies using gels are receiving the spotlight as a stable technique to conserve painting layers and remove synthetic resin-based fixatives. Various gels have been used to conserve cultural assets since the 1980s due to advantages such as reducing the volatilization of solvents during the cleaning process and controlling the penetration and dispersion of solvents into applicable objects (Stulik et al., 2004). The gel cleaning system is widely applied in the preservation treatment of murals because the cleaning agent hardly remains on the surface of the mural and it is easy to apply even to the porous surface. The painting layers of murals are relatively sensitive compared to general art paintings, so they are easily affected by cleaning materials and techniques. In particular, painting layers that received fixative treatment with synthetic resins with stronger properties than the materials used in the murals require more caution to remove the fixatives, and thus, validating the materials and technical research of the gel cleaners is needed.

Therefore, it is necessary to stabilize the fixative applied painting layers during previous interventions to conserve the painting layers of the Payathonzu Temple murals, and gel cleaning system were studied to remove poly (vinyl acetate) fixatives for this purpose. This gel cleaning system study evaluated the properties of the gel cleaners made by using the cleaning materials studied for the Bagan murals and evaluated the removability of the PVAc treated on the mural paintings. Afterward, the applicability was evaluated by fabricating mockup samples reflecting the characteristics of the techniques used to produce the mural paintings in the Payathonzu Temple.

In Part 1 of this study, six types of gel cleaners were produced by mixing three types of gelling agents $\left(\mathrm{Nevek}^{\circledR}\right.$, Laponite ${ }^{\mathbb{}} \mathrm{RD}$, Carbopol ${ }^{\mathbb{}} 980$ ) and two types of organic solvents (Acetone, Dimethyl carbonate) to compare their properties and removability. As the conditions of gel cleaners confirmed through the tests may have different effects depending on the characteristics of the materials and techniques used to create the mural paintings, Part 2 will focus on fabricating mockup samples reflecting these characteristics and conducting applicability tests to investigate the removal effect and stability of the gel cleaners.

\section{THEORETICAL BACKGROUND}

\subsection{Conservation state of Payathonzu Temple}

According to previous studies, the murals of the Payathonzu Temple suffered damage due to peeling, exfoliation, and contamination of the painting layers and the cracks, breakage, and lifting of walls. The surface of the murals is glossy from the floor to the height of human reach due to excessive fixative treatment in the past, and some cases displayed discoloration (e.g., yellowing) and fixative drippings. As a result of irradiating UV light to areas that received fixative treatment, residual fixative stains were confirmed through the difference in fluorescence reaction
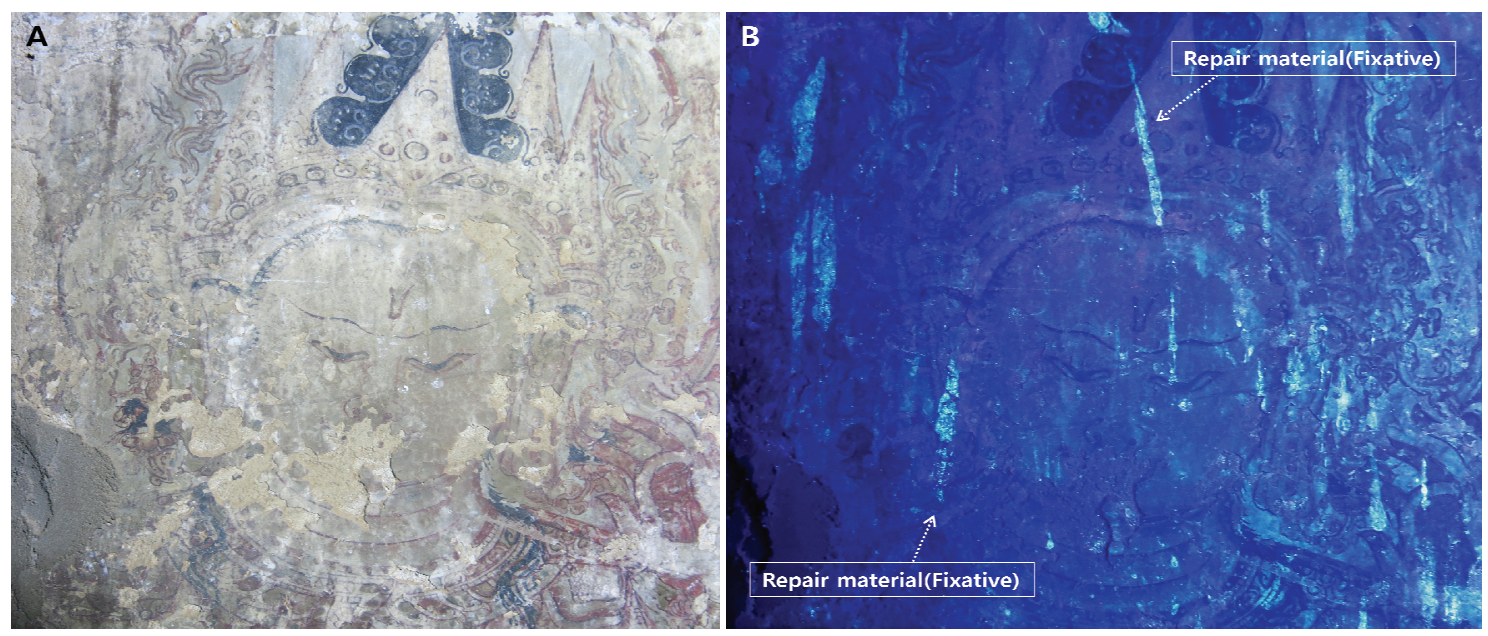

Figure 1. Mural painting under visible light (A) and ultraviolet light (B). 

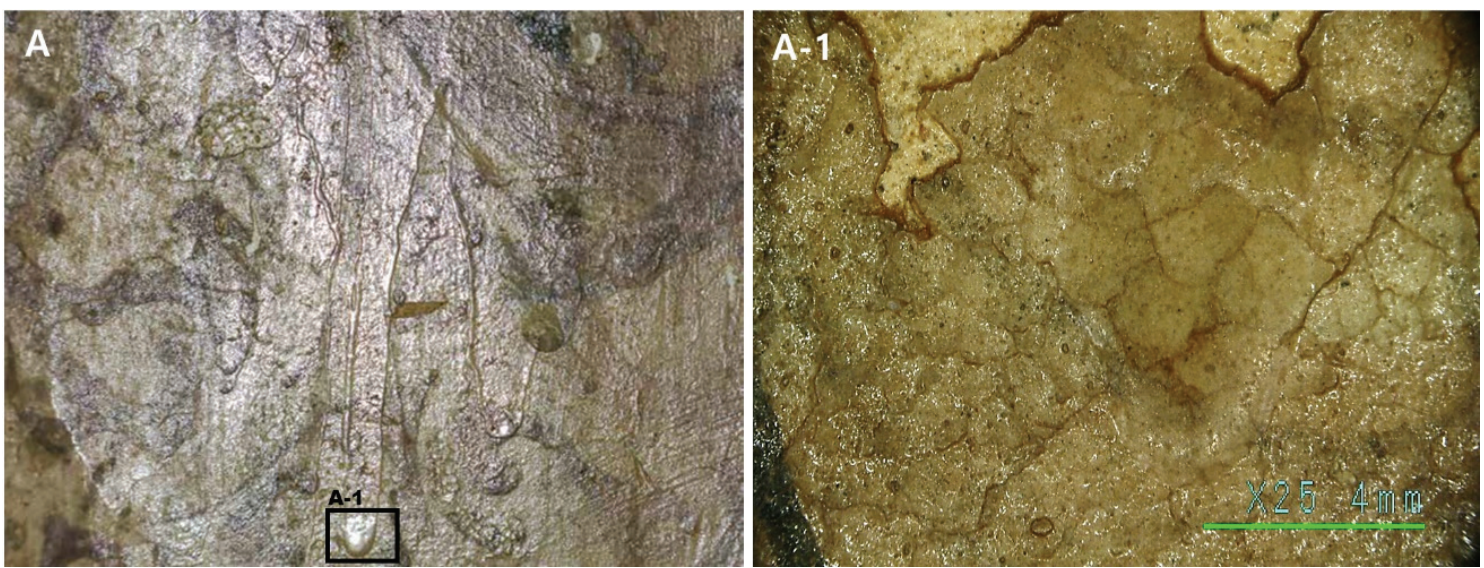

Figure 2. Excessive fixative region (A: glossy, A-1: crack - exfoliation).

(Figure 1). As a result of using a digital microscope to observe the surface on which fixatives formed thick films, cracks, peeling, and gloss were observed (Figure 2). Such damages were caused by the difference in physical properties between the fixatives and the painting layer, and the difference in physical properties between these materials may cause more damages in the long term. Currently, the fixatives applied to the murals during past interventions are causing cracks and peeling of the painting layer and undermining the aesthetics due to excessive gloss. As above, the fixatives used as repair materials in the past are one of the main factors hindering the conservation of the painting layers of the murals in the Payathonzu Temple (Korea Culture Heritage Foundation et al., 2019).

\subsection{Cleaning research trends in Bagan, Myanmar}

Research to conserve the Bagan ruins in Myanmar began with the help of international organizations such as United Nations Educational, Scientific and Cultural Organization (UNESCO) and International Centre for the Study of the
Preservation and Restoration of Cultural Property (ICCROM) after the major earthquake in 1975. More than 40 studies related to conservation have been conducted since Pierre Pichard, from UNESCO, investigated the conditions of the temple and the murals and documented the necessary treatment after the earthquake in 1976. The main content is about the status of temples and murals, the cause of damage, and the treatment applied, and Table 1 shows the details related to removing the fixatives and cleaning the surface of the painting layers.

Chemical approaches were used to remove the fixatives and clean the old contaminants on the surface of the painting layers, such as using cotton swabs dipped in solvents or applying solvents on Japanese paper. However, repeated studies revealed the risk of applying solvents directly to the surface of the murals. Therefore, most of the treatments were performed by mixing solvents and water or by using surfactants. Recently, many studies have been conducted on using cellulose pulp as a poultice or using gelling agents (e.g., Carbopol ${ }^{\circledR} 940, \mathrm{Nevek}^{\circledR}$ ) mixed with solvents to avoid applying the solvents directly to mural paintings.

Table 1. List of references of cleaning the surface on Bagan's mural paintings

\begin{tabular}{c|c|l|c}
\hline No & Year & \multicolumn{1}{|c}{ Title } & Publication \\
\hline 1 & 1976 & The Restoration of Pagan & UNESCO \\
\hline 2 & 1982 & $\begin{array}{l}\text { Mission Report-Technical Assistance for the Conservation of the Mural Paintings and } \\
\text { Stuccoes at Pagan, Burma }\end{array}$ & ICCROM \\
\hline 3 & 1983 & Conservation of Mural Paintings Pagan, Burma & ICCROM \\
\hline 4 & 1985 & Conservation of Mural Paintings and Stuccoes Pagan, Burma & ICCROM \\
\hline
\end{tabular}


Study on the Gel Cleaning System for Removal of Poly (vinyl acetate) Fixative ‥ / Yeong Gyeong Yu, Gyu-Seong Han, Hwa Soo Lee, Kyeong Soon Han I 373

\begin{tabular}{|c|c|c|c|}
\hline 5 & 986 & Iission Report-Conservation of Mural Paintings Pagan, Burma & ICCROM \\
\hline 6 & 88 & estoration Interventions on a 12th Century Cloth Painting from Pagan, Burma & UNESCO \\
\hline 7 & 1991 & $\begin{array}{l}\text { Mission Report-Conservation of Mural Paintings and External Stuccoes Bagan, Union } \\
\text { of Myanmar }\end{array}$ & ICCROM \\
\hline 8 & 991 & Conservation of Mural Paintings and External Stuccoes Pagan, Union of Myanmar & ICCROM \\
\hline 9 & 993 & Conservation of Mural Paintings and External Stuccoes Pagan, Union of Myanmar & UNESCO \\
\hline 10 & 993 & Conservation of Mural Paintings and External Stuccoes Pagan, Union of Myanmar & UNESCO \\
\hline 11 & 93 & Conservation of Mural Paintings, External Stuccoes and Stone Buildings & UNESCO \\
\hline 12 & 94 & onservation of Mural Paintings and External Stuccoes Pagan, Union of Myanmar & UNESCO \\
\hline 13 & 2012 & $\begin{array}{l}\text { Propositions for the Conservation-Restoration of Mural Paintings and Carved Stuccoes } \\
\text { in Bagan }\end{array}$ & UNESCO \\
\hline 14 & 13 & raining Course in Mural Painting and Stucco Carving Conservation in Bagan & UNESCO \\
\hline 15 & 2013 & $\begin{array}{l}\text { India-Myanmar Cooperation Project Structural Conservation and Chemical Reservation } \\
\text { of Ananda Temple, Bagan, Myanmar }\end{array}$ & $\begin{array}{l}\text { Archaec } \\
\text { Survey }\end{array}$ \\
\hline 16 & 2014 & $\begin{array}{l}\text { India-Myanmar Cooperation Project Structural Conservation and Chemical Preservation } \\
\text { of Ananda Temple, Bagan, Myanmar }\end{array}$ & $\begin{array}{l}\text { Archaeological } \\
\text { Survey of India }\end{array}$ \\
\hline 17 & 2015 & $\begin{array}{l}\text { Training Workshop on Emergency Conservation Intervention of Decorative Works at } \\
\text { Bagan }\end{array}$ & UNESCO \\
\hline 18 & 2017 & mergency and First Aid Treatments on the Mural Paintings & UNESCO \\
\hline 19 & 2017 & $\begin{array}{l}\text { Guidance Note in Approaches for Conservation of Mural Paintings } \\
\text { and Architectural Decorative Works at pagan }\end{array}$ & UNESCO \\
\hline 20 & 2017 & $\begin{array}{l}\text { India-Myanmar Cooperation Project Structural Conservation and Chemical Preservation } \\
\text { of Ananda Temple, Bagan, Myanmar }\end{array}$ & $\begin{array}{l}\text { Archaeologic: } \\
\text { Survey of Ind }\end{array}$ \\
\hline 21 & 2017 & $\begin{array}{l}\text { Recommendations on the Protection and Conservation of Mural Paintings and } \\
\text { Architectural Decorative Works of } 2012 \text { Ananda-ok-kyaung at Pagan }\end{array}$ & UNESCO \\
\hline 22 & 2018 & $\begin{array}{l}\text { Technical Recommendations to Improve the Use of Materials, Techniques and } \\
\text { Methodologies for the Conservation of Architectural Decorative Works at Pagan }\end{array}$ & UNESCO \\
\hline 23 & 2018 & $\begin{array}{l}\text { A Study on the Current State of Temple Murals of Bagan Ruins and Method of } \\
\text { Conserving Mural Paintings of Payathonzu Temple }\end{array}$ & $\mathrm{KCHF}$ (Korea) \\
\hline 24 & 2019 & Lokahteikpan Wall Painting Project, pagoda 1580 & TNRICP(Japan) \\
\hline 25 & 2019 & Scientific Analysis of Materials and Making Conservation Manual for Bagan Murals & KCHF(Korea) \\
\hline
\end{tabular}

UNESCO; United Nations Educational Scientific and Cultural Organization, ICCROM; International Centre for the Study of the Preservation and Restoration of Cultural Property, KCHF; Korea Cultural Heritage Foundation, TNRICP; Tokyo National Research Institute of Cultural Properties.

\section{MATERIALS AND METHODS}

\subsection{Materials}

\subsubsection{Fixative}

Poly (vinyl acetate) was selected as a fixative based on the analysis results of the murals of Payathonzu Temple. Poly (vinyl acetate) in the form of beads was dissolved in toluene to make a $10 \%$ solution.

\subsubsection{Gelling agents and organic solvents}

Gel cleaners were prepared by mixing 3 types of gelling agents and 2 types of organic solvents.

A gelling agent is a substance that increases the viscosity of a liquid solvent to make it a solid state. Depending on the type, the control characteristics according to the surface action and solvent diffusion are different. In this study, focusing on materials that are miscible with solvents and that can be applied to vertical or irregular surfaces, Three gelling agents $\left(\right.$ Nevek $^{\circledR}$, Laponite ${ }^{\circledR} \mathrm{RD}$, Carbopol $\left.^{\circledR} 980\right)$ were selected (Figure 3). 


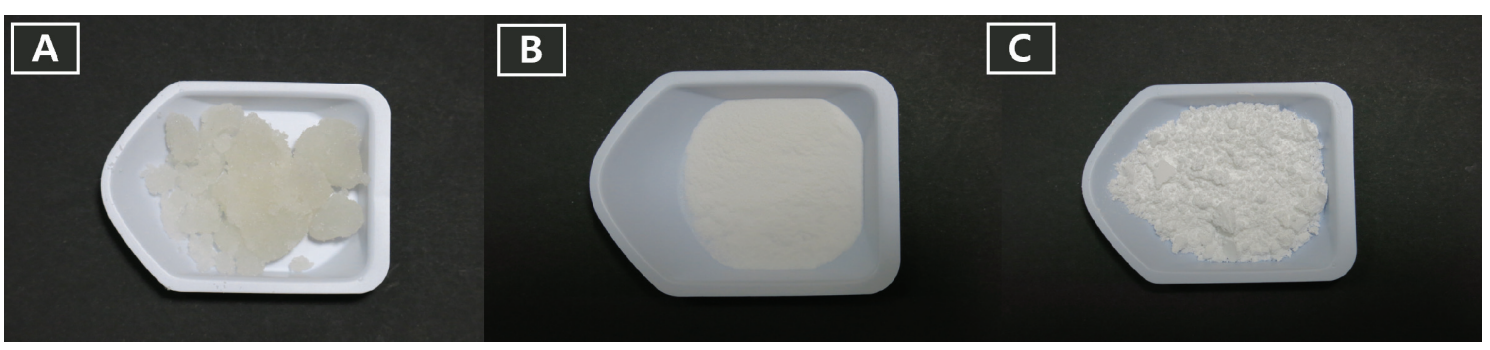

Figure 3. Gelling agent (A: Nevek $^{\circledR}$, B: Laponite ${ }^{\circledR} \mathrm{RD}, \mathrm{C}$ : Carbopol $^{\circledR} 980$ ).

Nevek (Nevek ${ }^{\circledR}$, C.T.S, Italy) is a material made based on ingredients extracted from agar, which is hard and has thermoplastic properties. In addition, it can be mixed with organic solvents as well as water, so it is used to remove synthetic resins such as water-sensitive objects or old Vinavil. There have been reports of cases in which Nevek ${ }^{\circledR}$ is applied to remove the synthetic resin used for fixing the murals, and it has also been used to remove the fixing agent from the murals of the Loka-hteik-pan temple in Bagan (Yoshifumi et al., 2019).

Laponite $^{\circledR}$ is a synthetic siliceous clay that forms an ionic colloidal gel in water. The main components are silicon oxide $\left(\mathrm{SiO}_{2}, 59.2 \%\right)$ and magnesium oxide (MgO, 27.5\%). Laponite ${ }^{\mathbb{R}} \mathrm{RD}$ (Laponite ${ }^{\mathbb{R}} \mathrm{RD}$, Conservation Support System, Italy) used in the experiment is a standard grade of Laponite ${ }^{\circledR}$ and has been widely used in the conservation field due to its ability to extract water-soluble substances from porous objects (Ling, 1991; Lee et al., 1997; Monger, 2002; Warda et al., 2007). Looking at overseas cases, it has been studied as a material for cleaning contaminants on the surface of ceramics, and it has also been studied in the field of cleaning contaminants from paper relics. In Korea, it was used for fixative removal of painting layers of mud wall murals (Lee et al., 2018).

Carbopol $^{\circledR}$ is a synthetic polymer with a carboxyl group $(-\mathrm{COOH})$ in which acrylic acid is polymerized. It can be applied to various materials because it can be mixed with organic solvents as well as water. In the field of conservation of cultural properties, it was mainly used as a thickener to remove surface contaminants or resin applied to the coating layer. Carbopol ${ }^{\mathbb{}} 980$ (Carbopol ${ }^{\mathbb{}} 980$, Lubrizol, USA) used in the experiment has low toxicity because it is polymerized in a co-solvent system of ethyl acetate and cyclohexane. Carbopol $^{\circledR} 940$ with similar properties to Carbopol ${ }^{\circledR} 980$ was used in the study of removing the old coating layer from the murals of the Ananda-ok-kyaung temple in Bagan (Lunsford, 2017).

Acetone $\left(\mathrm{CH}_{3} \mathrm{COCH}_{3}\right)$ and dimethyl carbonate (Dimethyl Carbonate (DMC, $\left.\left(\mathrm{CH}_{3} \mathrm{O}\right)_{2} \mathrm{CO}\right)$ were selected as solvents that can dissolve the fixing agent applied to the murals of Payathonzu Temple and have low toxicity. Both solvents have a purity of $99 \%$ or more and are manufactured by Samchun chemical Co., Ltd.

\subsection{Gel cleaner preparation}

Six types of gel cleaners (NA, LA, CA, ND, LD, CD) were prepared by mixing three gelling agents $\left(\mathrm{N}\right.$ : Nevek ${ }^{\mathbb{Q}}$, L: Laponite ${ }^{\mathbb{R}} \mathrm{RD}, \mathrm{C}$ : Carbopol ${ }^{\mathbb{}} 980$ ) and two solvents (A: acetone, D: dimethyl carbonate), as shown in Figure 4, Table 2 shows the recipe of gel cleaners.

\subsection{Evaluation methods}

\subsubsection{Properties of gel cleaner}

The properties of the gel cleaners were evaluated to investigate what kind of effect they would have when applied to remove the fixatives from the murals of the Payathonzu Temple. The hydrogen ion concentration $(\mathrm{pH})$, viscosity, and weight loss rates were measured, which are the factors that directly affect the removability.

The hydrogen ion concentrations were measured using a pH meter (P15, iSTEK, Korea), and the concentrations of NA and ND were measured after eluting in distilled water for more than 24 hours. The average was derived after measuring the same gel cleaner three times.

Viscosity was measured using a digital viscometer (Viscometer DV2T, Brookfield, Canada) for 1 minute after setting the rotation speed to $0.1 \mathrm{rpm}$ with an LV-04 (64) spindle at $17 \pm 1^{\circ} \mathrm{C}$. The average value was derived after measuring the viscosity of the same gel cleaner five times. 


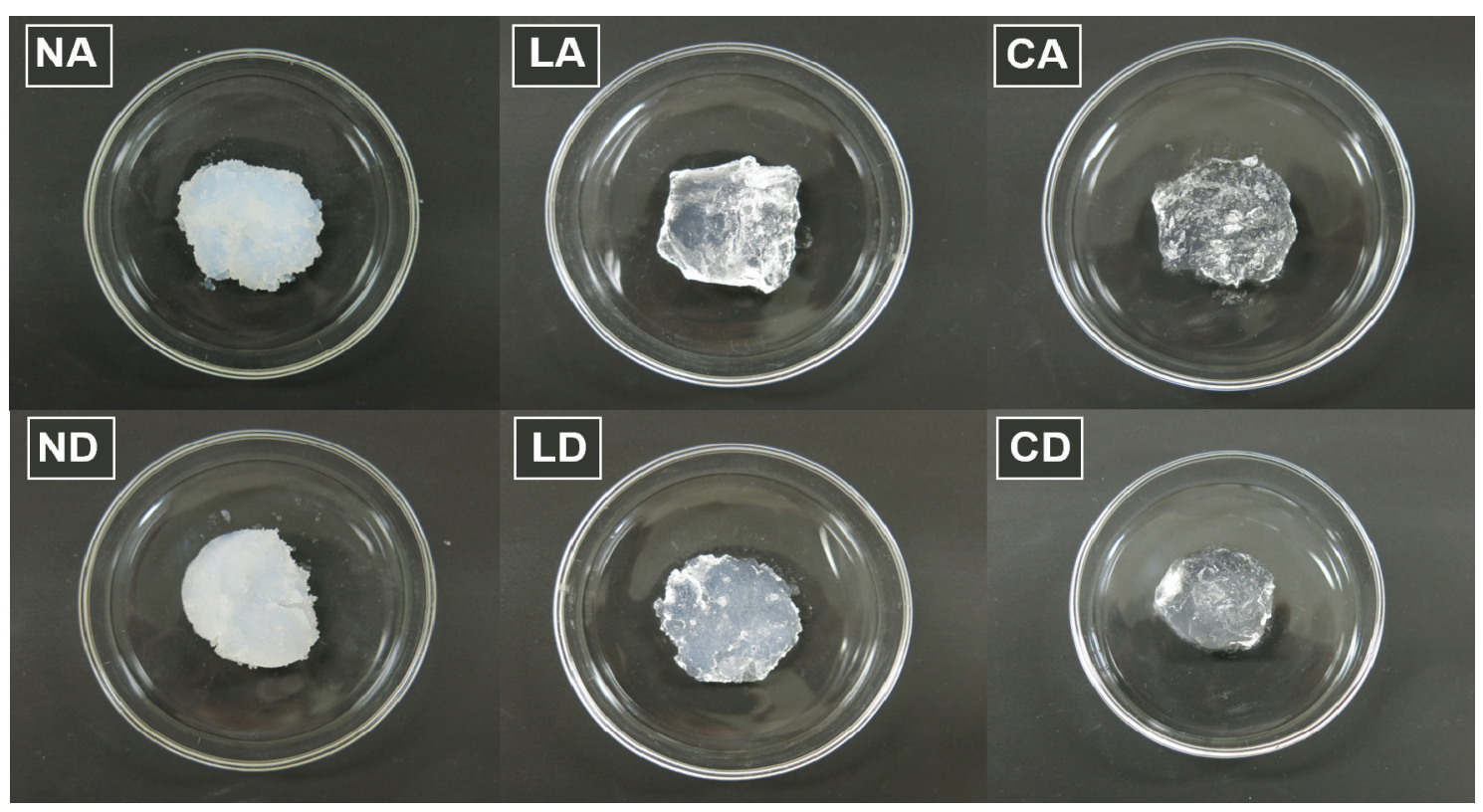

Figure 4. Manufactured gel cleaners.

Table 2. Recipe of gel cleaners

\begin{tabular}{lcccccc}
\hline \multicolumn{1}{c}{ Gel cleaners } & NA & LA & CA & ND & LD & CD \\
\hline Nevek $^{\circledR}$ & 40 & - & - & 40 & - & - \\
Laponite $^{\circledR}$ RD & - & 5 & - & - & 5 & - \\
Carbopol $^{\circledR 980}$ & - & - & 3 & - & - & 3 \\
\hline Water & - & 57 & 56.4 & - & 57 & 56.4 \\
Acetone & 60 & 38 & 37.6 & - & - & - \\
Dimethyl carbonate & - & - & - & 60 & 38 & 37.6 \\
TEA & - & - & 3 & - & - & 3 \\
\hline
\end{tabular}

Values are presented as \%.

The weight loss was calculated after measuring the weight to check the properties of each gel cleaner at the intervals of 30 minutes, 1 hour, 2 hours, 3 hours, 6 hours, 12 hours, and 24 hours. The same amount and volume of each gel cleaner were applied to a petri dish $(\varnothing 60 \times 15 \mathrm{~mm})$ to measure the weight of the cleaners. The conditions were divided into exposing the surface of the gel cleaners to the atmosphere and covering the gel cleaners with polyethylene vinyl to limit evaporation. The average values were obtained and compared after measuring each gel cleaner three times.

\subsubsection{Removability of gel cleaner}

The properties of the gel cleaners and their ability to remove the synthetic resin fixatives were evaluated and compared according to the application time (30 minutes, 1 hour, 2 hours). A certain amount of synthetic resin fixative was applied on a glass petri dish $(\varnothing 60 \times 15 \mathrm{~mm})$ to minimize interference from the applied samples. To apply the same conditions for each gel cleaner during the tests, the gel cleaners were applied in a certain amount and volume after placing rayon paper (TNT55, CTS, Italy) on the fixatives. To compare the differences according to the gel cleaner type and the application time, the degree of removal on the surface was observed through a stereoscopic microscope (SMZ-800N, Nikon, Japan), and then the removal rate was calculated using the weight before and after removal. The average removal 
rate was obtained after measuring three times for each gel cleaner.

\section{RESULT AND DISCUSSION}

\subsection{Properties of gel cleaner}

As a result of evaluating the properties of the gel cleaners, all of them had a pH between 6 and 10 (Figure 5). NA and $\mathrm{ND}$, which used $\mathrm{Nevek}^{\circledR}$ as the gelling agent, showed values close to neutral, and CA and CD, which used Carbopol ${ }^{\mathbb{}} 980$ as the gelling agent, had weak acidity. LA and LD, which used Laponite ${ }^{\mathbb{R}} \mathrm{RD}$ as the gelling agent, had weak alkalinity. All of the conditions were in the range of weakly acidic to weakly alkaline, indicating a stable condition for mural application

In the case of using the same gelling agent, there was no difference in the viscosity of each gel cleaner according to the added solvent. However, the viscosity according to the gelling agents was in the order of Carbopol $^{\mathbb{}} 980>$ Laponite ${ }^{\circledR} \mathrm{RD}>\mathrm{Nevek}^{\circledR}$ (Figure 6). These results show that the gelling agent has a significant effect on the gel cleaner's viscosity. The difference in viscosity can change the mobility of the solvent mixed in the gel cleaner and the solubilization rate of fixatives (Volpi, 2017), which is a significant factor in fixative removal and painting layer stability.

The weight loss rate was compared under two conditions: exposing the surface of the gel cleaners to the atmosphere and limiting evaporation by covering the cleaners with polyethylene vinyl. In the case of exposing the surface to the atmosphere, the weight was reduced by up to $17 \%$ after 24 hours, whereas the weight was reduced by up to $4.6 \%$ when limiting evaporation (Table 3, 4, Figure 7). In the case of using the same gel cleaners under different exposure conditions, the weight loss rate was in the range of $0.5 \%$ to $13.7 \%$, but the evaporation of solvents for each cleaner showed a similar trend. Overall, the values were high in the order of $\mathrm{NA}>\mathrm{ND}>\mathrm{LA}>\mathrm{CA}>\mathrm{LD}>\mathrm{CD}$.

When using the same gelling agent, the gel cleaner mixed with acetone had a relatively higher weight loss rate than the one mixed with dimethyl carbonate, and these results were attributed to the properties of the mixed solvent. The weight change of the solvent varies depending on the boiling point (bp), and the lower the boiling point $\left(\mathrm{bp}<100^{\circ} \mathrm{C}\right)$, the faster it evaporates at room temperature (Pianorsi, 2016). In

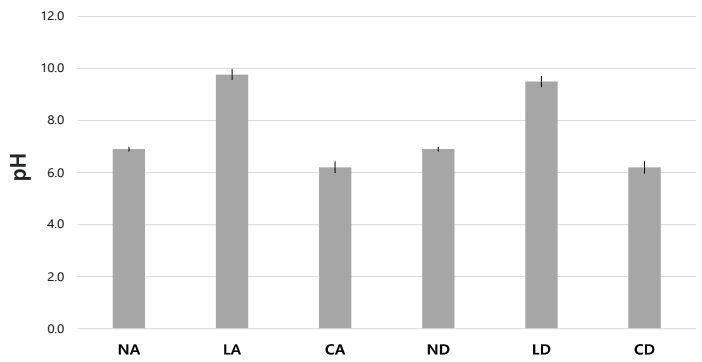

Figure 5. $\mathrm{pH}$ of gel cleaners (error bar: standard deviation).

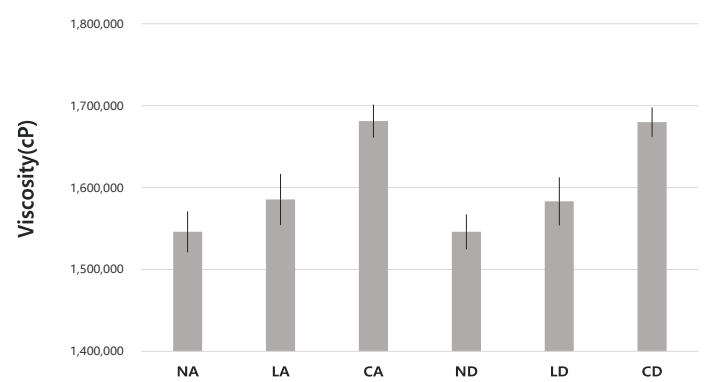

Figure 6. Viscosity of gel cleaners (error bar: standard deviation).

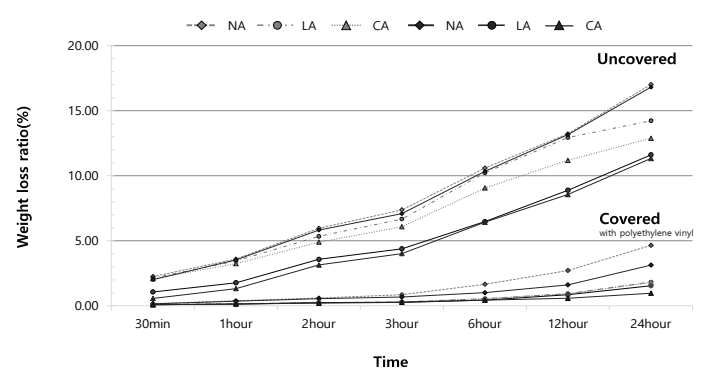

Figure 7. Weight loss ratio of gel cleaners.

addition, when setting the evaporation rate of butyl acetate to 1.0 , acetone is 6.22 , and dimethyl carbonate is 3.22 . Acetone has a lower boiling point than dimethyl carbonate and has a faster evaporation rate, which affected the weight loss rate of the gel cleaners according to the solvent. In the case of using the same solvent, the weight loss rate was high in the order of Nevek ${ }^{\circledR}>$ Laponite $^{\circledR} \mathrm{RD}>$ Carbopol $^{\circledR} 980$. When using the same solvent, the gel cleaners mixed with Laponite ${ }^{\circledR} \mathrm{RD}$ and $\mathrm{Carbopol}^{\mathbb{}}{ }^{\mathbb{9}} 980$ showed relatively similar ranges, but the cleaners mixed with Nevek $^{\circledR}$ showed differences up to $5 \%$ compared to those mixed with Laponite ${ }^{\circledR} \mathrm{RD}$ and $\mathrm{Carbopol}^{\circledR} 980$. These results are caused by the difference in viscosity of the mixed gelling agents. High viscosity limits the mobility of the solvent, so the higher the condition, the lower the evaporation rate of the solvent. 
Table 3. Weight loss ratio of gel cleaners, uncovered (units: \%)

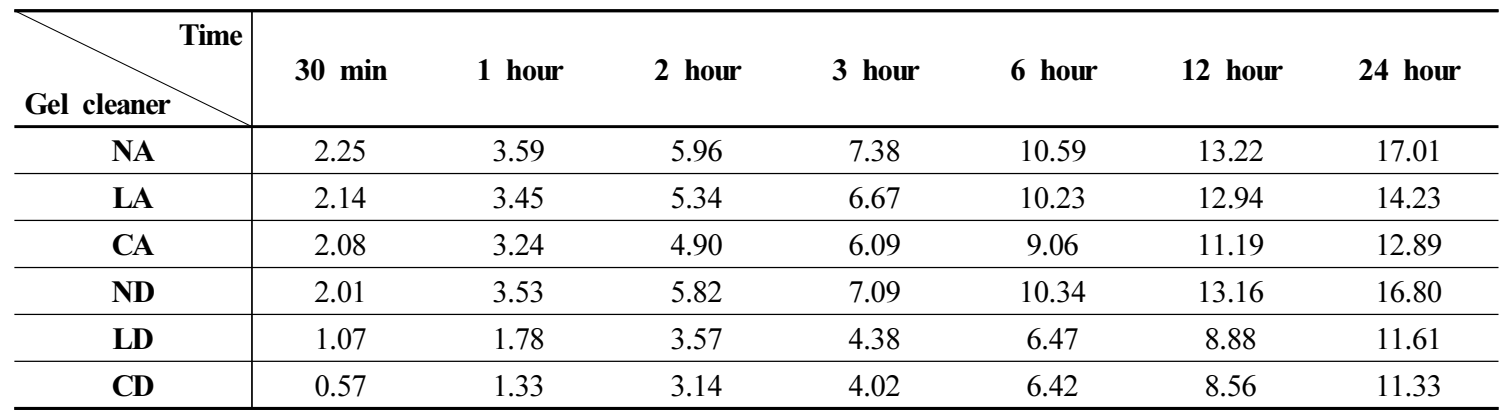

Table 4. Weight loss ratio of gel cleaners, covered (units: \%)

\begin{tabular}{c|ccccccc}
\hline Gel cleaner & To min & $\mathbf{1}$ hour & $\mathbf{2}$ hour & $\mathbf{3}$ hour & $\mathbf{6}$ hour & $\mathbf{1 2}$ hour & $\mathbf{2 4}$ hour \\
\hline NA & 0.17 & 0.39 & 0.59 & 0.85 & 1.66 & 2.72 & 4.66 \\
\hline LA & 0.09 & 0.17 & 0.25 & 0.30 & 0.56 & 0.94 & 1.83 \\
\hline CA & 0.08 & 0.17 & 0.22 & 0.30 & 0.55 & 0.92 & 1.78 \\
\hline ND & 0.14 & 0.36 & 0.55 & 0.68 & 1.01 & 1.61 & 3.14 \\
\hline LD & 0.08 & 0.14 & 0.25 & 0.28 & 0.45 & 0.85 & 1.55 \\
\hline CD & 0.08 & 0.14 & 0.21 & 0.26 & 0.43 & 0.58 & 0.98 \\
\hline
\end{tabular}

Although there were differences in the degree depending on the gel cleaner, the change in the weight loss rate according to the application time appeared to be similar.

\subsection{Removability of gel cleaner}

As a result of observing the surface (Figure 8), there were differences according to the solvent and gelling agent mixed in the gel cleaner and the application time. Compared to the gel cleaner mixed with acetone, the one mixed with dimethyl carbonate showed relatively better removability and uniform aspects of removal. In addition, the removal effect was the best at 2 hours when using the same gel cleaner.

As a result of evaluating the removing power through weight changes, the removal rate increased as the application time increased, in the order of $\mathrm{ND}>\mathrm{CD}>\mathrm{LD}>\mathrm{NA}>\mathrm{CA}>$ LA (Table 5, Figure 9).

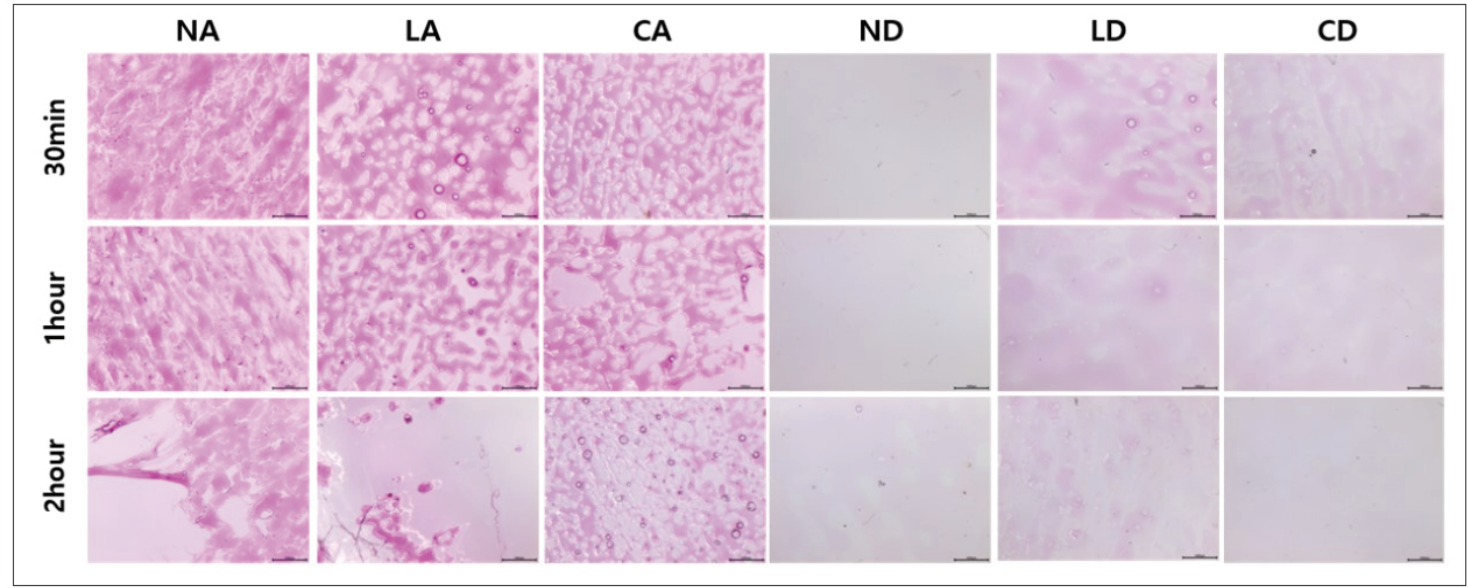

Figure 8. Removal degree of gel cleaners. 


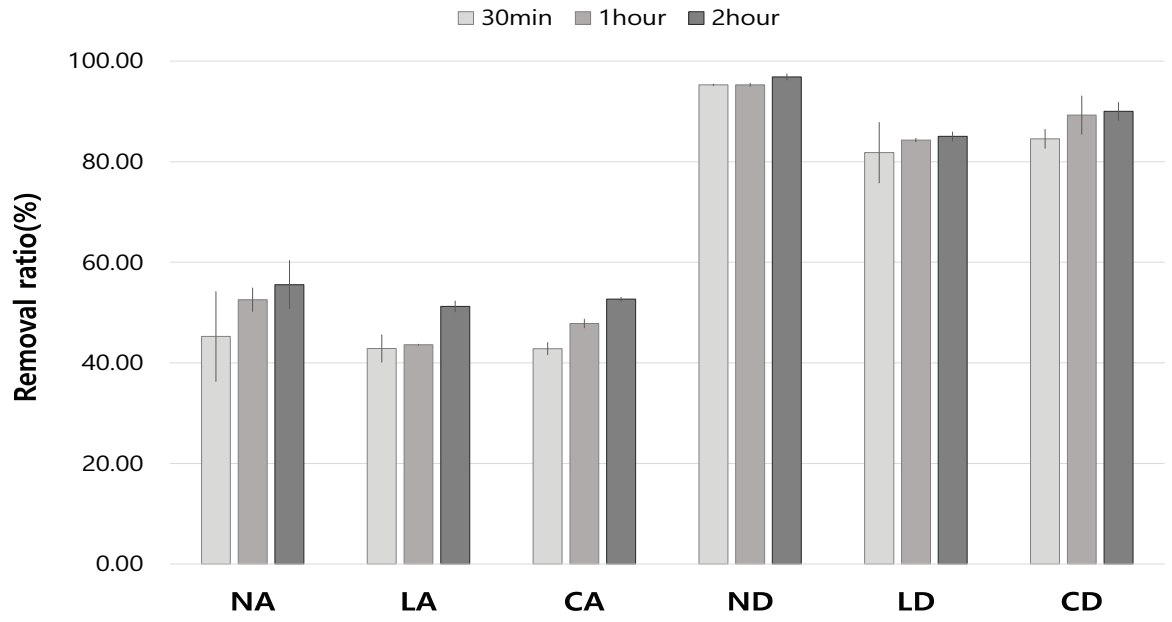

Figure 9. Removal ratio of gel cleaners (error bar: standard deviation).

Table 5. Removal ratio of gel cleaners (units: \%)

\begin{tabular}{c|cccccc}
\hline Gel cleaner & NA & LA & CA & ND & LD & CD \\
\hline 30 min & 45.27 & 42.86 & 42.81 & 95.27 & 81.81 & 84.56 \\
\hline $\mathbf{1}$ hour & 52.57 & 43.61 & 47.84 & 95.30 & 84.31 & 89.28 \\
\hline 2 hour & 55.57 & 51.22 & 52.68 & 96.87 & 85.02 & 90.02 \\
\hline
\end{tabular}

As a result of comparing the removal rate according to the solvents, the removal rate of the gel cleaner mixed with dimethyl carbonate was higher than the cleaner mixed with acetone, and a difference of up to $50 \%$ was found even when using the same gelling agent. This is because dimethyl carbonate has higher solvency for poly (vinyl acetate) than acetone, so dimethyl carbonate has a relatively significant effect on solubilizing synthetic resin fixatives within the same period.

As a result of comparing the removal rate according to the gelling agents, the gel cleaners using the same solvent were in the order of $\mathrm{Nevek}^{\circledR}>\mathrm{Carbopol}^{\circledR} 980>$ Laponite $^{\circledR}$ RD. A maximum difference of up to $13 \%$ was observed depending on the gelling agent used. These results are considered to be influenced by the difference in viscosity of each gelling agent. Nevek ${ }^{\circledR}$ has a lower viscosity than other materials, so the ratio of the area where the solvent comes into contact with the target surface is high, which increases the speed of fixative solubilization and increases the removability. The viscosity of Carbopol ${ }^{\circledR} 980$ is higher than Laponite ${ }^{\mathbb{R}} \mathrm{RD}$, so the evaporation amount of the solvent is relatively low compared to the application time, resulting in higher removability.

\section{CONCLUSION}

The gel cleaning system was studied to secure the stability of the painting layers while effectively removing the poly (vinyl acetate) fixatives excessively applied to the painting layers of the Payathonzu temple murals. Six gel cleaners were fabricated by mixing three gelling agents and two solvents to evaluate and compare their properties and removability.

In terms of the gel cleaner's power to remove fixatives, the gel cleaners mixed with dimethyl carbonate were higher than those mixed with acetone. This is a result of dimethyl carbonate solubilizing poly (vinyl acetate) more effectively than acetone. In addition, the removal rate increased as the gel cleaner application time increased.

When using the same solvent, the removal effect of the gelling agents was in the order of Nevek ${ }^{\circledR}>$ Carbopol $^{\circledR} 980$ $>$ Laponite $^{\circledR} \mathrm{RD}$. In the case of Nevek ${ }^{\circledR}$, the viscosity is lower 
than that of other materials, resulting in a higher ratio of the area where the solvent comes into contact. Since Carbopol $^{\circledR} 980$ has a higher viscosity than Laponite ${ }^{\circledR} \mathrm{RD}$, the evaporation amount of the solvent is relatively low compared to the application time, so it is judged to have high removal power.

Consequently, the cleaning effect of the gel cleaners was highly correlated with its fixative solubilization rate, and the solubilization rate depended on the solvent's solubility and volatility and the gelling agent's solvent release characteristics. The gel cleaning system studied in this experiment has a removal effect on the poly (vinyl acetate) fixative, and it was found that selective cleaning was possible because conditions that could affect it were selectively applied.

In the follow-up study, the stability of the gel cleaning system will be established through a pilot test. The gel cleaners will be prepared and applied to the controlled samples under conditions that consider the conservation conditions, material, and manufacturing technique characteristics of murals of Payathonzu temple.

\section{REFERENCES}

Korea Culture Heritage Foundation, Konkuk University and Chungbuk National University, 2018, A study on the current state of temple murals of Bagan ruins and methods of conserving mural paintings of Payathonzu temple. 259.

Korea Culture Heritage Foundation, Konkuk University and Chungbuk National University, 2019, Scientific analysis of materials and making conservation manual for Bagan murals. 167 .

Lee, H.S., Han, K.S., and Chung, Y.J., 2015, Techniques and methodology of mural painting conservation, Buyeo-gun,
Korea National University of Cultural Heritage.

Lee, K.M., Moon, H.Y., Yu, Y.G. and Kim, S.K., 2018, Experimental study on poultices applying to remove fixative (Paraloid B-72) on Earthen Mural Painting. Journal of Conservation Science, 34(6), 569-580.

Lee, L. M., P Rogers, V. L. Oakley, and J. Navarro., 1997, Investigations into the use of Laponite as a poulticing material in ceramics conservation, $\mathrm{V} \& \mathrm{~A}$ Conservation Journal 22, 9-11.

Ling, D.,1991, Laponite poulticing. Conservation News, 46, 10-11.

Lunsford, R.L., 2017, Recommendations on the protection and conservation of mural paintings and architectural decorative works of 2162 Ananda-ok-kyaung at Pagán, Rome, UNESCO.

Monger, G., 2002, Treatment of a Roman child's lead coffin liner, Conservation News 77, 36-37.

Pianorsi, M.D., 2016, Synthesis and application of novel materials for cleaning and protection of historical documents, Ph.D. dissertation, University of Floence.

Stulik, D., Miller, D., Khanjian, H., Carlson, J., Khandekar, N., Wolbers, R. and Petersen, W.C., 2004, Solvent Gels for the cleaning of works of art: the residue question, California, The Getty Conservation Institute.

Volpi, F., 2017, Green strategies for the cleaning of works of art: Setting up of an analytical protocol for the evaluation of cleaning. Ph.D. Dissertation, University of Bologna, Bologna.

Warda, J., Bruckle, I., Bezur, A. and Kushel, D., 2007, Analysis of agarose, carbopol, and laponite Gel poultices in paper conservation. Journal of the American Institute for Conservation, 46(3), 276-279.

Yoshifumi, M., Corella, D.M., Franceschini, Amadori L. and Camaiti M., 2019, Lokahteikpan Wall Painting Project, pagoda 1580, Tokyo. Tokyo National Research Institute for Cultural Properties. 